\title{
Participatory Networks:
} \section{The Library As Conversation}

The goal of the technology brief is to familiarize library decision-makers with the opportunities and challenges of participatory networks. In order to accomplish this goal the brief is divided into four sections (excluding an overview and a detailed statement of goal):

- a conceptual framework for understanding and evaluating participatory networks;

- a discussion of key concepts and technologies in participatory networks drawn primarily from Web 2.0 and Library 2.0;

- a merging of the conceptual framework with the technological discussion to present a roadmap for library systems development; and

- a set of recommendations to foster greater discussion and action on the topic of participatory networks and, more broadly, participatory librarianship.

This summary will highlight the discussions in each of these four topics. For consistency, the section numbers and titles from the full brief are used.

$\mathrm{K}$ nowledge is created through conversation. Libraries are in the knowledge business. Therefore, libraries are in the conversation business. Some of those conversations span millennia, while others only span a few seconds. Some of these conversations happen in real time. In some conversations, there is a broadcast of ideas from one author to multiple audiences. Some conversations are sparked by a book, a video, or a Web page. Some of these conversations are as trivial as directing someone to the bathroom. Other conversations center on the foundations of ourselves and our humanity.

It may be odd to start a technology brief with such seemingly abstract comments. Yet, without this firm, if theoretical, footing, the advent of Web 2.0, social networking, Library 2.0, and participatory networks seems a clutter of new terminology, tools, and acronyms. In fact, as will be discussed, without this conceptual footing, many library functions can seem disconnected, and the field that serves lawyers, doctors, single mothers, and eight-year olds (among others) fragmented.

The scale of this technology brief is limited; it is to present library decision-makers with the opportunities and challenges of participatory networks. It is only a single piece of a much larger puzzle that seeks to present a cohesive framework for libraries. This framework not only will fit tools such as blogs and wikis into their offerings (where appropriate), but also will show how a more participatory, conversational approach to libraries in general can help libraries better integrate current and future functions. Think of this document as an overview or introduction to participatory librarianship. Readers will find plenty of examples and definitions of Web 2.0 and social networking later in this article. However, to jump right into the technology without a larger framework invites the rightful skepticism of a library organization that feels constantly buffeted by new technological advances. In any environment with no larger conceptual founding, to measure the importance of an advance in technology or practice selection of any one technology or practice is nearly arbitrary. Without a framework, the field becomes open to the influence of personalities and trendy technology. Therefore, it is vital to ground any technological, social, or policy conversation into a larger, rooted concept. As Susser said, "to practice without theory is to sail an uncharted sea; theory without practice is not to set sail at all." ${ }^{1}$ For this paper, the chart will be conversation theory.

The core of this article is in four sections:

- a conceptual framework for understanding and evaluating participatory networks;

- a discussion of key concepts and technologies in participatory networks drawn primarily from Web 2.0 and Library 2.0;

- a merging of the conceptual framework with the technological discussion to present a sort of roadmap for library systems development; and

- a set of recommendations to foster greater discussion and action on the topic of participatory networks and, more broadly, participatory librarianship.

It is recommended that the reader follow this order to get the big picture; however, the second section should be a useful primer on the language and concepts of participatory networks.

\section{Library as a facilitator of conversation}

Let us return to the concept that knowledge is created through conversation. This notion stretches back to Socrates and the Socratic method. However, the specific foundation for this statement comes from conversation theory, a means of explaining cognition and how people learn. ${ }^{2}$ It is not the purpose of this article to provide a

R. David Lankes (jdlankes @iis.syr.edu) is Director and Associate Professor, Joanne Silverstein (jlsilver@iis.syr.edu) is Research Professor, and Scott Nicholson (scott@scottnicholson.com) is Associate Professor at the Information Institute of Syracuse, (N.Y.) Syracuse University's School of Information Studies. 
detailed description of conversation theory, a task already admirably accomplished by Pask. Rather, let us use the theory as a structure upon which to hang an exploration of participatory networking and, more broadly, participatory librarianship.

The core of conversation theory is simple: people learn through conversation. Different communities have different standards for conversations, from the scientific community's rigorous formalisms, to the religious community's embedded meaning in scripture, to the sometimes impenetrable dialect of teens. The point remains, however, that different actors establish meaning through determining common definitions and building upon shared concepts.

The library has been a place where we facilitate conversations, though often implicitly. The concept of learning through conversation is evidenced in libraries in such large initiatives as information literacy and teaching critical thinking skills (using such meta-cognitive approaches as self-questioning), and in the smaller events of book groups, reference interviews, and speaker series. Library activities such as building collections of artifacts (the tangible products of conversation) inform scholars' research through a formal conversation process where ideas are supported with evidence and methods. Similarly, preservation efforts, perhaps of wax cylinders with spoken word content or of ancient maps that embody an ongoing dialogue about the shape and nature of the physical world, seek to save, or at least document, important conversations.

Common use of the word "conversation" is completely in accordance with the use of the term in conversation theory. The term is, however, more specifically defined as an act of communication and agreement between a set of agents. So, a conversation can be between two people, two organizations, two countries, or even within an individual. How can a conversation take place within an individual? Educators and school librarians may be familiar with the term "metacognition," or the act of reflecting on one's learning. ${ }^{3}$ Yet, even the most casual reader will be familiar with the concept of debating oneself ("if I go right, I'll get there faster, but if I go left I can stop by Jim's . . ."). The point is that a conversation is with at least two agents trying to come to an understanding. Also note that those two agents can change over time. So, while Socrates and Plato are dead, the conversation they started about the nature of knowledge and the world is carried forward by new generations of thinkers-same conversation, different agents.

People converse, organizations converse, states converse, societies converse. The requirements, in the terms of conversation theory, are two cognitive systems seeking agreement. The results of these conversations, what Pask would call "cognitive entanglements," are books, videos, and artifacts that either document, expand, or result from conversations. ${ }^{4}$ So, while one cannot converse with a book, that book certainly can be a starting point for many conversations within the reader and within a larger community.

If the theory is that conversation creates knowledge, the library community has added a corollary: the best knowledge comes from an optimal information environment, one in which the most diverse and complete information is available to the conversant(s). Library ethics show an implicit understanding of this corollary in the advocacy of intellectual freedom and unfettered access. Libraries seek to create rich environments for knowledge and have taken the stance that they are not in the job of arbitrating the conversations that occur or the appropriateness of the information used to inform those conversations. As will be discussed later, this belief in openness of conversations will have some far-reaching implications for the library collection and is an ideal that can never truly be met. For now, the reader may take away that conversation theory is very much in line with current and past library practice, and it also shows a clear trajectory for the future.

This viewpoint's value is not just theoretical; it has real consequences and uses. For example, much of library evaluation has been based on numeric counts of tangible outputs: books circulated, collection size, reference transactions, and so on. Yet this quantitative approach has been frustrating to many who feel they are counting outcomes but not getting at true impact of library service. Librarians may ask themselves, "Which numbers are important . . . and why?" If libraries focused on conversations, there might be some clarity and cohesion between statistics and other outcomes. Suddenly, the number of reference questions can be linked to items cataloged or to circulation numbers . . . they are all markers of the scope and scale of conversations within the library context. This approach might enable the library community to better identify important conversations and demonstrate direct contributions to these conversations across functions. For example, a school district identifies early literacy as important. There is a discussion about public policy options, new programs, and school goals to achieve greater literacy in $\mathrm{K}-5$. The library should be able to track two streams in this conversation. The first is the one libraries are accustomed to counting; that is, the library's contribution to K-5 literacy (participation in book talks, children's events, circulation of children's books, reference questions, and so on). But the library also can document and demonstrate how it furthered the conversation about children's literacy in general. It could show the resources provided to community officials. It could show the literacy pathfinders that were created. The point of this example is that the library is both participant in the conversation (what we do to promote early literacy) and facilitator of conversation (what we do to promote public discourse). 
The theoretical discussion leads us to a discussion about the second topic of this technology brief: pragmatic aspects of the knowledge as conversation approach, or a participatory approach, as it will be called. As new technologies are developed and deployed in the current environment of limited resources, there must be some means of evaluating their utility. A technology's utility is appropriately measured against a given library's mission, which is, in turn, developed to respond to the needs of the community that library serves. First, however, let us identify some of the new technologies and describe them briefly.

\section{Participatory networking, social networks, and Web 2.0}

Let us now move from the theoretical to the operational. The impetus behind this article is the relatively recent emergence of a new group of Internet services and capabilities. Suddenly, terms such as wiki, blog, mashup, Web 2.0, and biblioblogosphere have become commonplace. As with any new wave of technological creation, these terms can seem ambiguous. They also come wrapped in varying amounts of hype. They may all, however, be grouped under the phenomenon of participatory networking.

While we now have a conceptual framework to evaluate these technologies that support participatory networking (for example, do they further conversations), we still need to know the basics of the terminology and technologies.

This section outlines key concepts in the pragmatics of participatory networking. The section after this one will join the theoretical and operational to outline key challenges and opportunities for the library world. We begin with Web 2.0.

\section{Web 2.0}

Much of what we call participatory networking, at least the technological foundation of it, stems from developments in Web 2.0.5 As with many buzzwords, the exact definition of Web 2.0 is not clear. It is more an aggregation of concepts that range from software development (loosely coupled Application Programming Interfaces [APIs] and the ease of incorporating features across platforms) to abstractions (the user is the content). What pervades the Web 2.0 approach is the notion that Internet services are increasingly facilitators of conversations. The following sections describe some of the characteristics of Web 2.0.

Web 2.0 characteristic: social networks

A core concept of Web 2.0 is that people are the content of sites; that is, a site is not populated with information for users to consume. Instead, services are provided to individual users for them to build networks of friends and other groups (professional, recreational, and so on). The content of a site, then, comprises user-provided information that attracts new members of an ever-expanding network. Examples include:

- Flickr. Flickr (www.flickr.com) provides users with free Web space to upload images and create photo albums. Users then can share these photos with friends or with the public at large. Flickr facilitates the creation of shared photo galleries around themes and places.

- The Cheshire Public Library. The Teen Book Blog (http:/ / cpltbb.wordpress.com) at the Cheshire Public Library offers book reviews created only by the students who use the library.

- Memorial Hall Library. The Memorial Hall Library in Andover, Massachusetts, offers podcasts of poetry contests in which the content is created by students (www.mhl.org/teens/audio/index.htm).

- Libraries in MySpace. MySpace searches show that there are MySpace sites for hundreds of individual libraries and scores of library groups. Alexandrian Public Library (APL), for example, has established a site at MySpace (www.myspace.com/teensatapl). This practice is growing among public libraries and is an attempt to reach out to users in their preferred online environments. In this venue, the more friends a library's MySpace site has, the more successful it may be considered. As of this writing, APL had seventy-five friends and fifteen comments. The Brooklyn College Library had 2,195 friends and 270 comments.

\section{Web 2.0 characteristic: wisdom of crowds}

There has been some research into the quality of mass decision-making. ${ }^{6}$ That research shows how remarkably accurate groups are in their judgments. Web 2.0 pools large groups of users to comment on decisions. This aggregation of input is facilitated by the ready availability of social networking sites. Certainly, this approach of community organization and verification of knowledge also has its detractors. Many, for example, question the wisdom seen in some entries of Wikipedia. Yet, recent articles have compared this mass editing process favorably to traditional sources of information, such as the Encyclopedia Britannica. ${ }^{7}$ Examples include:

- eBay. eBay has perhaps the most studied and copied community policing and reputation systems. All buyers and sellers can be rated. The aggregation of many users' experiences create a feedback score that is equivalent to a group credibility rating (see figure 1 ). These kinds of group feedback systems can now be seen in most major Internet retailers.

- LibraryThing. LibraryThing.com makes book recom- 
mendations based on the collective intelligence of all users of the site. The greater the pool of collective intelligence, the more information available to the user for decision-making.

- The Diary Project. The Diary Project Library (www. diaryproject.com) is a non-profit organization that encourages teens to write about their day-to-day experiences growing up. The goal of this site is to encourage communication among teens of all cultures and backgrounds, provide peer-to-peer support, stimulate discussion, and generate feedback that can help ease some of the concerns teens encounter along the way and let them know that they are not alone. To that end, the site comprises thousands of entries in twenty-four categories. Because of the great number of entries, most youth can find helpful materials.

\section{Web 2.0 characteristic: loosely coupled APIs}

An API provides a set of instructions (messages) that a programmer can use to communicate between applications. APIs allow programmers to incorporate one piece of software they may not be able to directly manipulate (code) into another. For example, Google Maps has made a public API that allows Web page designers to include satellite images into their Web pages with little more than a latitude and longitude. ${ }^{8}$ APIs vary in their ease of integration. Loosely coupled APIs allow for very easy integration using high-level scripting languages such as Javascript ${ }^{9}$. Examples include:

- Google Maps. Google Maps displays street or satellite maps showing markers on specific locations provided by an external source with simple sets of longitudes and latitudes. It becomes extremely easy to create Geographic Information Systems with little knowledge of GIS principles.

- Flickr. Flickr provides easy means to integrate hosted images into other Web pages or applications (as with a Google Map that shows images taken at a specific location).

- YouTube. YouTube (www.youtube.com) provides users with the capability to upload and comment upon video on the Internet. It also allows for easy integration of the videos into other Web pages and blogs. With a simple line of HTML code, anyone can access streaming video for their content.

\section{Web 2.0 characteristic: mashups}

Mashups are combinations of APIs and data that result in new information resources and services. ${ }^{10}$ This ease of incorporation has led to an assumption of a "right to remix." In the world of open source software and the creative commons, the right to remix refers to a growing expectation among Internet users that they are not limited by the interfaces and uses presented to them by a

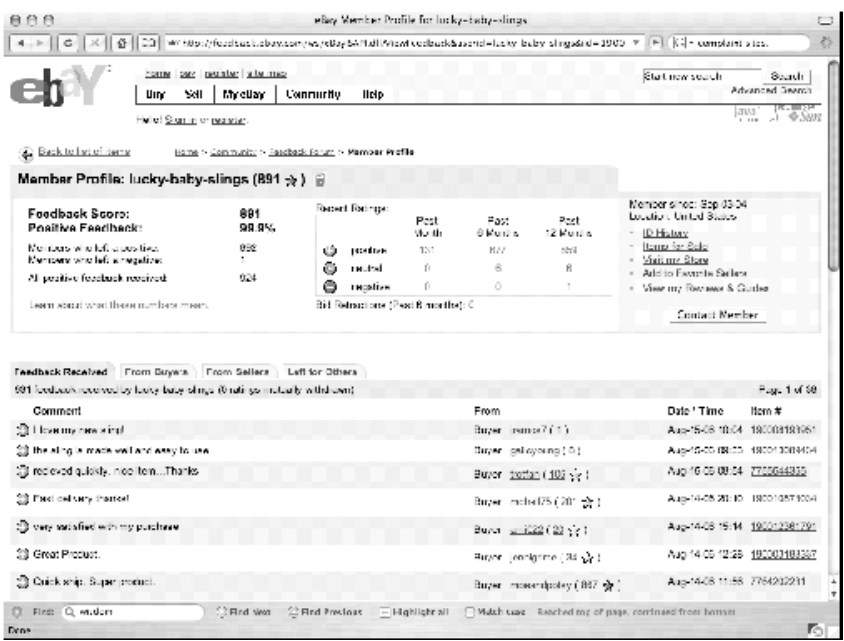

Figure 1. A seller's profile shows a potential buyer the eBay community's current estimation of a seller's credibility.

single organization. Examples include:

- ChicagoCrime.org. An often-cited example of a mashup is ChicagoCrime.org, which uses Google Maps to plot crime data for the city of Chicago. Users can now see exactly which street corner had the most murders. Figure 2 shows a marker at the location of every homicide in Chicago from November 2, 2005, to August 2, 2006.

- Book Burro. Book Burro (http://bookburro.org/ about.html) "is a Web 2.0 extension for Firefox and Flock. When it senses you are looking at a page that contains a book, it will overlay a small panel which when opened lists prices at online bookstores such as Amazon, Buy, Half (and many more) and whether the book is available at your library."

- Library Lookup. The MIT Library LookUp Greasemonkey Script for Firefox (http://libraries. mit.edu/help/lookup.html) searches MIT's Barton catalog from an Amazon book screen.

\section{Web 2.0 characteristic: permanent betas}

The concept of a permanent beta is, in part, a realization that no software is ever truly complete so long as the user community is still commenting upon it. For example, Google does not release services from beta until it has achieved a sufficient user base, no matter how fixed the underlying source code is. ${ }^{11}$ Permanent beta also is a design strategy. Large applications are broken into smaller constituent parts that can be manipulated separately. This allows large applications to be continually 
developed by a more diverse and distributed community (as in open source). Examples include:

- Google Labs. Google has a site named "Google Labs" (http://labs.google.com) that puts out companygenerated tools and services. In fact, part of a Google employee's work time is dedicated to creating the resources and tools through personal projects and exploration. These tools and services remain a part of the "lab" until they are finished and have sufficient user bases. Projects (see figure 3) range from the simple (Google Suggest, which provides a dropdown box of possible search queries as you being to type your search terms) to the extensive (Google Maps, which started as a Google Lab project).

- MIT Libraries. The MIT Libraries are experimenting with new technologies to help make access to information easier. The tools below are offered to the public with an appeal for feedback and additional tools, and the there is a permanent address designed just to collect feedback from the beta-phase tools, which include:

- The New Humanities Virtual Browsery, which highlights new books and incorporates an RSS feed, the ability to comment on books, links to book reviews, availability information, and links to other books by the same author.

- The LibX-MIT Edition (http://libraries.mit. edu/help/libx.html), which is a Firefox toolbar that allows users to search the Barton catalog, Vera, Google Scholar, the SFX FullText Finder, and other search tools; it embeds links to MITonly resources in Amazon, Barnes \& Noble, Google Scholar, and NYT Book Reviews.

- The Dewey Research Advisor Business and Economics Q\&A (http:/ /libraries.mit.edu/help/ dra.html), which provides starting points for specific research questions in the fields of business, management, and economics.

\section{Web 2.0 characteristic: software gets better the more people use it}

An increasing number of Web 2.0 sites emphasize social networks, where these services gain value only as they gain users. Malcolm Gladwell recounts this principle and the work of Kevin Kelly with an earlier telecommunications network, the network of fax machines connected to the phone system:

The first fax machine ever made . . . cost about $\$ 2,000$ at retail. But it was worth nothing because there was no other fax machine for it to communicate with. The second fax machine made the first fax machine more valuable, and the third fax made the first two more valuable, and so on. ... When you buy a fax machine, then, what you are really buying is access to the entire

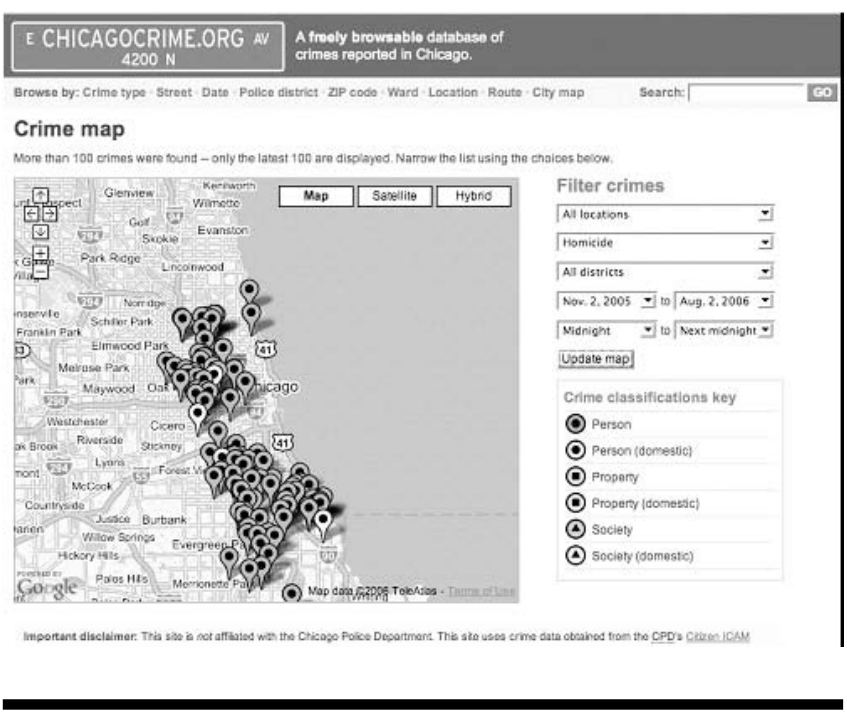

Figure 2: Screenshot of Chicagocrime.org

fax network-which is infinitely more valuable than the machine itself. ${ }^{12}$

With social networking sites, and all sites that seek to capitalize on user input (reviews, annotations, profiles, etc.), the true value of each site is defined by the number of people it can bring together. A classic example of this characteristic is Amazon. Amazon sells books and other merchandise, but, in reality, Amazon is very much about the marketing of information. Amazon gains tremendous value by allowing its users to review and rate items. The more people use Amazon and the more they comment, the more visibility these active users gain and the more credibility markers they take on.

\section{Web 2.0 characteristic: folksonomies}

A folksonomy is a classification system created in a bottom-up fashion with no central coordination. This differs from the deductive approach of such classifications systems as the Dewey Decimal System, where the world of ideas is broken into ten nominal classes. ${ }^{13}$ It also differs from other means of developing classifications where some central authority determines if a term should be included. In a folksonomy, the members of a group simply attach terms (or tags) to items (such as photos or blog postings), and the aggregate of these terms is seen as the classification. What emerges is a classification scheme that prioritizes common usage (the most-used tags) over semantic clarity (if most people use "car," but some use "cars," they are seen as different terms, and the tag "automobile" has no real relationship within the aggregate classification). Examples include: 
- PennTags. PennTags (http://tags.library.upenn.edu/ help) is a social bookmarking tool for locating, organizing, and sharing one's favorite online resources. Members of the Penn Community can collect and maintain URLs, links to journal articles, and records in Franklin, the online catalog, and VCat, the online video catalog. Once resources are compiled, users can organize them by assigning tags (free-text keywords) or by grouping them into projects according to specific preferences. PennTags also can be used collaboratively, as it acts as a repository of the varied interests and academic pursuits of the Penn community, and a user can find topics and other users related to his or her own favorite online resources.

- Hillsdale Teen Library. The Hillsdale Teen Library (www.flickr.com/photos/hillsdalelibraryteens) uses Flickr to post pictures of events at the Hillsdale Teen Library (figure 4). The resulting tag view is represented in figure 5. These tags allow users to easily retrieve the images in which they are interested.

There are more characteristics of Web 2.0, but these give some overall concepts.

\section{Core new technologies: AJAX and Web services}

As we have just discussed, Web 2.0 is little more than set of related concepts, albeit with a lot of value being currently attached to these concepts. These concepts are supported by two underlying technologies that have facilitated Web 2.0 development and brought a substantially new (and improved) user experience to the Web. The first is AJAX, which allows a more desktop-like experience for users. The second is the advent of Web services. These technologies are not necessary for Web 2.0 concepts, but they have made Web 2.0 sites much more compelling.

\section{AJAX}

AJAX stands for Asynchronous JavaScript and XML. ${ }^{14}$ It is a set of existing Web technologies brought together. At the most basic, AJAX allows a browser (the part the user interacts with) and a server (where the data resides) to send data back and forth without needing to refresh the entire Web page being worked on. Think about the Web sites you work with. You click on a link, the browser freezes and waits for the data, then draws it on the screen. Early versions of such sites as MapQuest would show a map. If you wanted to zoom into the map, you would press a zoom icon and wait while the new map, and the rest of the Web page was redrawn. Compare this to Google Maps, where you click in the middle of a map and drag left or right and the map moves dynamically. We are used to this kind of interaction in desktop applications. Click and drag has become second nature on the desktop, and AJAX is making it second nature on the Web, too.

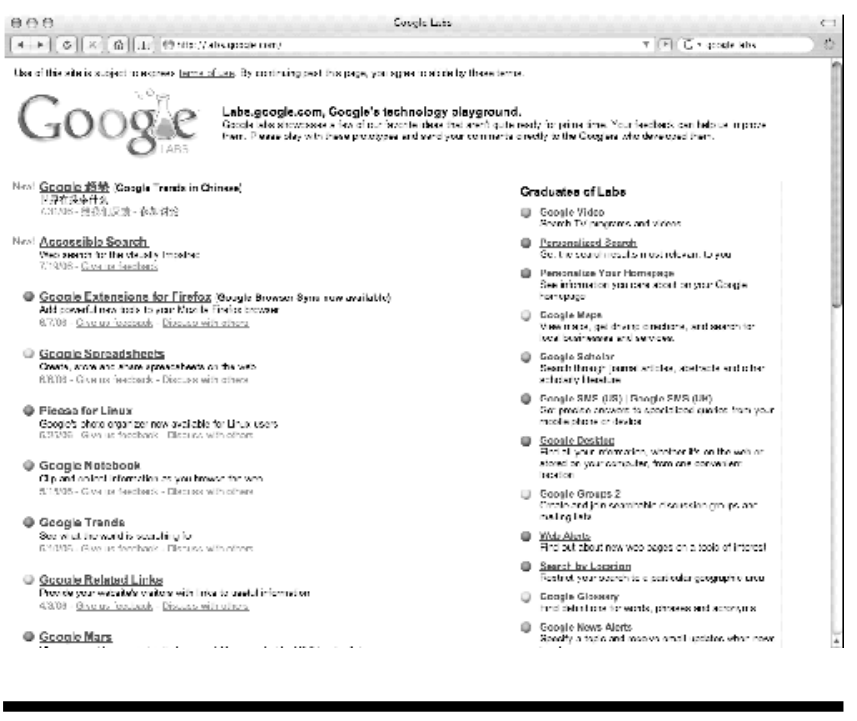

Figure 3: Screenshot of current Google Lab projects

Another AJAX advantage is that it is open and requires only light programming skills. Javascript on the client and almost any server-side scripting language (such as active server pages or PHP) are easily accessible languages. This fact allows for both fast development and easier integration with existing systems. As an example, it should now be easier to bring more interactive Web interfaces to existing online catalogs.

\section{Web services}

Web services allow for software-to-software interactions on the Web. ${ }^{15}$ Using Web protocols and XML, applications exchange queries and information in order to facilitate the larger functioning of a system. One example would be a system that uses an ISBN number to query multiple online catalogs and commercial vendors for availability (and price) of a book. This simple process might be part of a much larger library catalog that shows users a book and its availability. The point is, that unlike federated search systems such as Z39.50, Web services are small. They also tend to be lightweight (that is, limited in what they do), and are aggregated for greater functionality. This is the technological basis for the loosely coupled APIs discussed previously.

\section{Library 2.0}

Library 2.0 is a somewhat diffuse concept. Walt Crawford, in his extended essay "Library 2.0 and 'Library 2.0,'" found sixty-two different (and often contradictory) views and seven distinct definitions of Library 2.0.16 It is no wonder that people are confused. However, it is natural for emerging ideas and groups to function in an environ- 
ment of high ambiguity. For use in this technology brief, the authors see Library 2.0 as an attempt to apply Web 2.0 concepts (and some longstanding beliefs for greater community involvement) to the purpose of the library.

In the words of Ormsby, "The purpose of a library is not to ... showcase new gadgetry ... ; rather, it is to make possible that instant of insight when all the facts come together in the shape of new knowledge." ${ }^{\prime 17}$ In the case of Library 2.0, the new gadgetry discussed in the previous section comprises a group of software applications. How the applications are used will determine whether they support Ormsby's "instant of insight." Many libraries and librarians already are pursuing this goal. Some, for instance, are using blogs to reach other librarians, their own users (on their own Web sites), and potential users (using MySpace and other online communities). They are using wikis to deliver reports, teach information literacy, and serve as repositories. One has developed an API that allows WordPress posts to be directly integrated into a library catalog. Clearly, the Internet and newer tools that empower users seem to be aligned with the library mission. After all, librarians blogging and allowing the catalog to be mashed up can be seen as an extension of current information services.

But this abundance of new applications poses a challenge. Given the speed with which new tools are invented, librarians may find it difficult to create strategies that include all the desired services that they make possible. For every new application that becomes available, library administrators must decide whether it can serve the library, how to use it, and how to find additional resources to manage it (for example, "Now we can do this. But why should we?"). This problem stems from focusing excessively on the technology.

Librarians should instead focus on the phenomena made possible by the technology. Most important of these phenomena, the library invites participation. As Chad and Miller state:

Library 2.0 facilitates and encourages a culture of participation, drawing upon the perspectives and contributions of library staff, technology partners and the wider community. Library 2.0 means harnessing this type of participation so that libraries can benefit from increasingly rich collaborative cataloguing efforts, such as including contributions from partner libraries as well as adding rich enhancements, such as book jackets or movie files, to records from publishers and others.

Library 2.0 is about encouraging and enabling a library's community of users to participate, contributing their own views on resources they have used and new ones to which they might wish access.

With Library 2.0, a library will continue to develop and deploy the rich descriptive standards of the domain, whilst embracing more participative approaches that

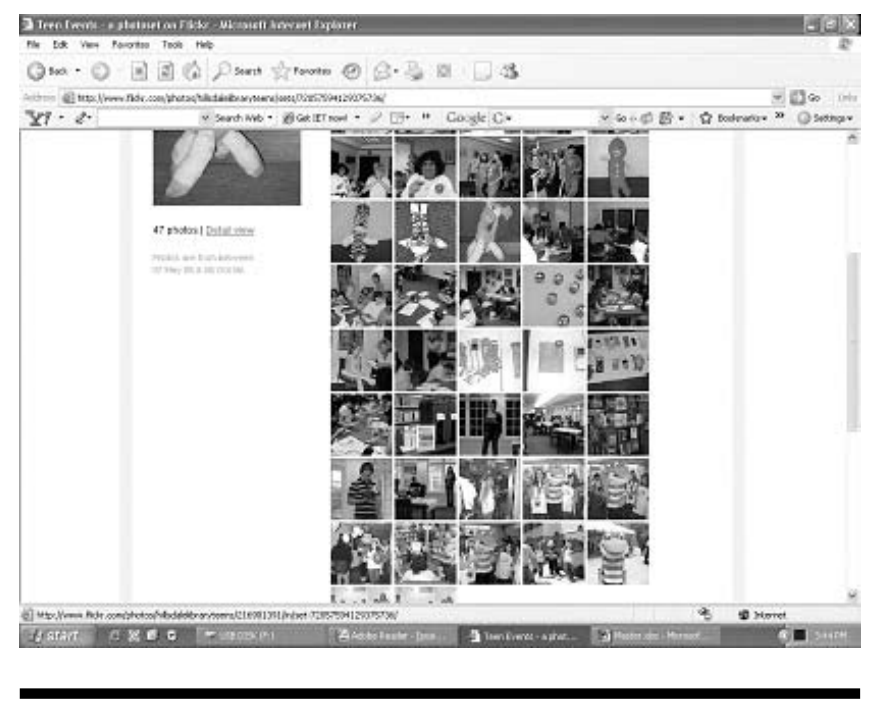

Figure 4: Hillsdale Teen Library

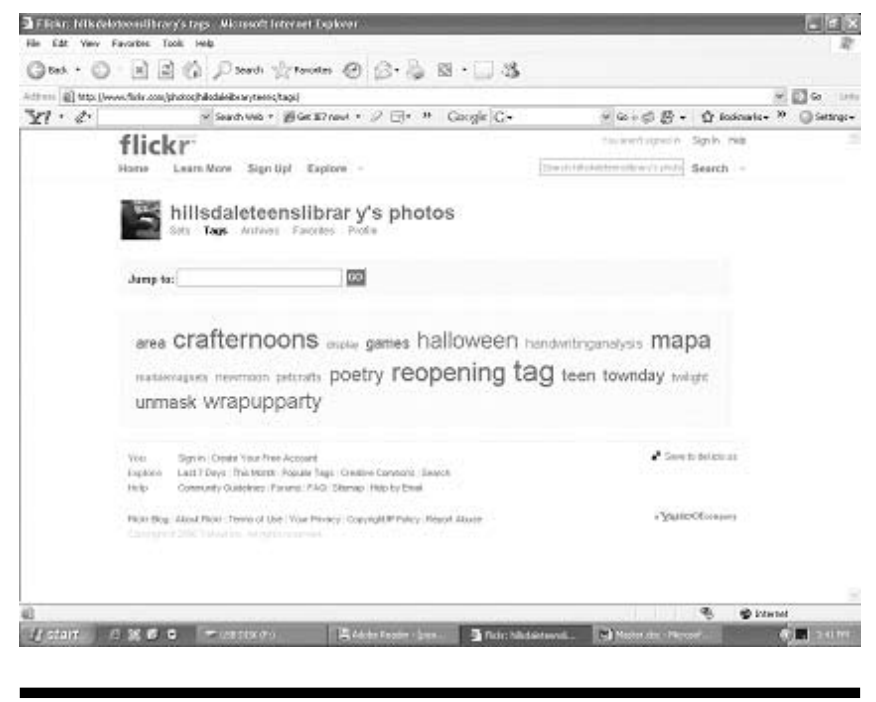

Figure 5: Hillsdale Teen Library Flickr site

encourage interaction with and the formation of communities of interest. ${ }^{18}$

The carte blanche statement that users participating in the library is "good," however, is insufficient. Library administers must ask, "What is the ultimate goal?"

In summary, current initiatives in the library world to bring the tools of Web 2.0 to the service of Library 2.0 are exciting and innovative, and, more to the point, they are supportive of the library's purpose. They may, however, incur costs, such as monitoring blogs and wikis, and cre- 
ating content and corresponding with users that stretch already inadequate resources even further.

Ultimately, the value of Library 2.0 concepts requires us to answer some important questions: will they be used to further knowledge, or will they simply create more work for librarians? What does the next version of Library 2.0 look like? Is its mission the same, and only the tools different? What makes the library different from MySpacesimply a legacy? Should we incorporate new services into the current library offerings? How do we, as facilitators of conversations, point the way to the next generation of library? It is hoped that some of the concepts in participatory librarianship may answer these questions and help further the innovations of the Library 2.0 community.

\section{Participatory networks}

The authors use the phrase "participatory networking" to encompass the concept of using Web 2.0 principles and technologies to implement a conversational model within a community (a library, a peer group, the general public, and so on). Why not simply adopt social networking, Web 2.0, or Library 2.0 for that matter? Let us examine each term's limitations:

- Social networking: Social network sites such as MySpace and Facebook have certainly captured public attention. They also have proven very popular. In their short life spans, these sites have garnered an immense audience (MySpace has been ranked one of the top destination sites on the Web) and drawn much attention from the press. ${ }^{19}$ Some of that attention, however, has been very negative. MySpace, for example, has been typified as a refuge for pedophiles and online predators. Even the television show Saturday Night Live has parodied the site for the ease with which users can create false personas and engage in risky online behaviors. ${ }^{20}$ To say you are starting a social networking site in your library may draw either enthusiastic support, vehement opposition ("social networking experiment in my library?!"), or simply confused looks. Add to the potential negative connotations the ambiguity of the term. Is a blog a social networking site? Is Flickr? To compound this confusion, the academic domain of social network theory predates MySpace by about a decade.

- Web 2.0: Ambiguity also dogs the Web 2.0 world. For some, it is technology (blogs, AJAX, Web services, and so on). For others, it is simply a buzzword for the current crop of Internet sites that survived the burst of the dot-com bubble. In any case, Web 2.0 certainly implies more than just the inclusion of users in systems.

- Library 2.0: As stated before, the term Library 2.0 is a vague term used by some as a goad to the library community. Further, this term limits the discussion of user-inclusive Web services to the library world. While this brief focuses on the library community, it also sees the library community as a potential leader in a much broader field.

So, ultimately, the authors propose "participatory networking" as a positive term and concept that libraries can use and promote without the confusion and limitations of previous language.

The phrase "participatory network" also has a history of prior use that can be built upon. It represents systems of exchange and integration and has long been used in discussions of policy, art, and government. ${ }^{21}$ The phrase also has been used to describe online communities that exchange and integrate information.

\section{Libraries as participatory conversations}

So where are we? We started with the abstract statement that knowledge is created through conversation. We then looked at the current landscape of technologies that can facilitate these conversations and showed examples of how libraries, other industries, and individuals are using these technologies. In this section we combine the larger framework with the technologies to see how libraries can incorporate participatory networks to further their knowledge mission.

\section{Participatory librarianship in action}

Let us look specifically at how participatory networks can be used in the library's role as facilitator of knowledge through conversation. An obvious example is libraries hosting blogs and wikis for their communities, creating virtual meeting spaces for individuals and groups. Indeed, these are increasingly useful functions for libraries. They meet a perceived need in the community and can generate excitement both within the library and in the community. The idea of creating online sites for individuals and organizations makes sense for a library, although it is not without difficulties (see the section on challenges and opportunities). Libraries also could use freely available (and increasingly easy to implement) open source software to create library versions of Wikipedia (with or without enhanced editorial processes). Another way for libraries to offer these services would be through a cooperative or other third-party vendor. Such a service easily can be seen as a knowledge management activity capturing and providing local expertise while linking this expertise to that produced at other libraries.

Another reason for libraries to engage in participatory networking is that one library can more easily collaborate 
with other libraries in richer dialogues. We currently have systems that connect our online catalogs and share resources through interlibrary loan. These conduits exist and can be used for the transferal of richer data, as has been proved through collaborative virtual reference systems. In our current systems, as in traditional library practice, when users are referred to other libraries, they are sent out and not brought back. In a participatory library setting, libraries would facilitate a conversation between the user, the community of the local library, and then through the developed conduits, other libraries and their communities. The end result would be a seamless web of libraries where the user can ignore the intricacies of the library's organization structure and boundaries, and in which the libraries are using the best local resources to meet local needs.

Bringing libraries seamlessly together to participate in conversations with a single user has another significant advantage: the Library would make it easy for users to join the conversation regardless of where they are, through the presentation of a single façade. There is, for example, only one Google, one Amazon, and one Wikipedia. Why should users have to search from among thousands of libraries to find the conversations they want? Participatory networking will be most effective when libraries work together, when the whole is greater than its parts.

We currently see elements of the participatory library in the OCLC Open Worldcat project. For example, users searching Google may come across a listing provided by OCLC. After selecting the entry for the book, the user can then jump to his or her own local library's information about the book. Users do not have to know which library to visit to find a book near them. Extending this concept to conversations, one goal of these participatory networks is to make it easier for the user to enter a conversation with the Library without having to work to discover their own specific entry points.

However, ensuring this effective seamless access to the Library will require more than simply adding elements of participatory networking around the library's edges. Adding services such as blogs and wikis may be seen merely as adjunct to current library offerings. As with any technological advance, scarce resources must be weighed against a desire to incorporate new services. Do we expand the collection, improve the Web site, or offer blogs to students? A better approach for making these kinds of decisions is to look at the needs of the community served in context with the commonly accepted, core tasks of a library, and see how they can be recast (and enhanced) as conversational, or participatory, tools. In point of fact, every service, patron, and access point is a starting point for a conversation. Let's start with the catalog.

If the catalog is a conversation, it is decidedly formal and, more importantly, one way. Think of today's catalog as the educational equivalent of a college lecture. A formal system is used to serve up a series of presentations on a given topic (selected by the user). The presentations are rigid in their construction (MARC, AACR2, and so on). They follow an abstract model (relevance scores, sometimes alphabetical listings), and provide minimal opportunities to the receiver of the information to provide feedback or input. They provide no constructive means for the user to improve or shape the conversation. Even recent advances in catalog functions (dynamic, graphical visualizations; faceted searching; simple search boxes' links to non-collection resources) do little more than make the presentation of information more varied. They are still not truly interactive because they do not allow user participation; they do not allow for conversation.

To highlight the one-way nature of the catalog, ask a simple question: what happens when the user doesn't find something? Do we assume that the information is there, but that the user is simply incapable of finding it (in which case the catalog presents search tips, refers the patron to an expert librarian who is capable, or offers more information literacy instruction)? Do we assume that the information does not exist (refer the patron to interlibrary loan, pass him or her on to a broader search engine)? Do we assume that the catalog itself is limited (refer the user to online databases, or other finding aids)? What if we assume that the catalog is just the current place a user is involving in an ongoing conversation -what would that look like?

How can such a traditionally rigid system (in concept, more than in any one feature set) be made more participatory? What if the user, finding no relevant information in the catalog, adds either the information or a placeholder for someone else to fill in the missing information? Possibly the user adds information from his or her expertise. However, assuming that most people go to a catalog because they don't have the information, perhaps the user instead begins a process for adding the information. The user might ask a question using a virtual reference service; at the end of the transaction, the user then has the option to add the question, along with the answer and associated materials, to the catalog. Or perhaps, the user simply leaves the query in the catalog for other patrons to answer, requesting to be notified when a response is posted. In that case, when a new user does a catalog search and runs across the question, he or she can provide an answer. That answer might be a textual entry (or an image, sound, or video), or simply a new query that directs the original questioner or new patrons to existing information in the catalog (user-created see also entries in the catalog).

The catalog also can associate conversations with any data point. For example, a user pulls up the record for a book she or he feels might be relevant to an information need she or he is having. This process starts a conversation between that user and the library, its users, and 
authors of associated works. The user can see comments and ratings associated with this book from not only users of this library, but users of other libraries. Also associated is a list of related works and the full audio of a lecture by the author. The user also might be directed to an inperson or online book group that is reading that book. The point is that the catalog facilitates a conversation as opposed to simply presenting what it "knows" about a topic and then stepping out of the process. The catalog, then, does not simply present information, but instead helps users construct knowledge by allowing the user to participate in a conversation.

There are other means of improving (and linking) systems in a conversational library. Take the implicit link between the catalog and circulation. Of course, these systems have always been linked in that items found in the catalog can be checked out, and checked out items have their status reflected in the catalog. But this kind of state information is a pretty meager offering. Imagine using circulation data to improve the actual functionality of the catalog. Take the example of a user who is searching the catalog for fictional books on magic. Currently, a relevance score between an item's metadata and the query is computed and then all the items are ranked in a retrieval set. This relevance score can be computed in many ways, but is usually based on the number of times a keyword appears in the record and the placement of that keyword in the metadata record (giving preference to terms appearing in certain MARC fields, such as titles). What is missing is the actual, real-world circulation of an item. Wouldn't it make sense, given such an abstract query, to present the user with Harry Potter first (but not exclusively)? What if we added circulation data to our relevance rankings: how many times this item has been checked out? It turns out that using a simple statistic is amazingly powerful. It is akin to Google's page rank algorithm that presents sites most linked to higher in the results. Also, for those worried that users would be flooded with only popular materials, studies show that while these algorithms do change the very top ranked material, the effect quickly fades so that the user can still easily find other materials. Another consideration for adjusting a search is to allow the user to tweak the algorithms used to retrieve works. In the example above, a user could turn off the popularity feature. The user also could toggle switches for currency, authority, and other facets of relevancy rankings.

The conversational model requires us to rethink the catalog as a dynamic system with data of varying levels of currency and, frankly, quality, coming into and out of the system. In a conversational catalog, there is no reason that some data can't exist in the catalog for limited durations (from years to seconds). Records of well-groomed physical collections may be a core and durable collection in the catalog, but that is only one of many types of infor- mation that could exist in the catalog space. Furthermore, even this core data can be annotated and linked to (and from) more transient media. So, the user might see a review from a blog as part of a catalog record on one day, but when she or he pulls the record up again in a few days, that review might be absent, the blog writer having withdrawn the comment. This is akin to weeding the collection; however, it would happen in a more dynamic fashion than occurs with the content on library shelves.

The conversational model also can be used in other areas of the library. What do we digitize? What do we select? What programs do we offer? What do we preserve? The empowered user can participate in answering all of these questions but does not replace the expert librarian; rather, the user contributes additional and diverse information and commentary.

In fact, the catalog scenario just proposed already assumes that the library catalog does more than store metadata. In order for the scenario to work, the catalog must store questions, answers, video, audio-in essence the catalog must be expanded and integrated with other library systems so that a final participatory library system can present a coherent view of the Library to patrons. The next section lays out a sort of roadmap for these enhancements and mergers.

\section{Framework for integration of participatory librarianship}

As has been noted, participatory networks and libraries as conversations are not brand new concepts sprung from the head of Zeus. Instead, they are means to integrate past and current innovations and create a viable plan forward. Figure 6 provides a sort of road map of how the library might make the transition from current systems to a truly participatory system. It includes current systems, systems under development (such as federated searching), and new concepts (such as the participatory library). It seeks to capture current momentum and push the field forward to a larger view instead of getting bogged down in the intricacies of any one development activity.

Along the left side of the graph are current library systems. While the terminology may differ from library to library, nearly every system can be found on today's library Web sites. By showing the systems together, the problems of user confusion and library management burden become obvious. Users must often navigate these systems based on their needs, and often with little help. Should they search the catalogs first, or the databases? Isn't the catalog really just another database? Which database do they choose? In our attempts to serve the users better by creating a rich set of resources and services, we have instead complicated their information-seeking lives. As one librarian puts it, "don't give me one more system I, or my patrons, have to deal with." 
From the array of systems on the left side, we can see that libraries have not been doing themselves any favors either. We are maintaining many systems, therefore making the calls for yet more systems not only impractical but unwise. The answer is to integrate systems, combining the best of each while discarding the complexity of the whole. The library world is in the midst of doing just that. This section seeks to highlight promising developments in integrating library systems well beyond the library catalog and to highlight not only an ideal endpoint, but also how this ideal system is truly participatory.

\section{Merging reference and community involvement}

The functional area furthest along in the integration of participatory librarianship is reference; as reference is most readily recognizable as a conversation, this comes as no surprise. Over the last decade, reference services have gone online and have led to shared reference services. More importantly, reference done online creates artifacts of reference conversations: electronic files than can be cleaned of personal information and placed in a knowledge base and used as a resource for other users. A new development in reference is the reference blog, in which multiple librarians and other users can be part of a question-answering community with conversations that can live on beyond a single transaction.

Another functional area of libraries that is already involved with participatory librarianship is community involvement. For decades, public libraries have supported local community groups through meeting spaces. Some libraries now are hosting Web spaces for local groups. As libraries incorporate participatory technologies into their offerings, they can create virtual places such as discussion

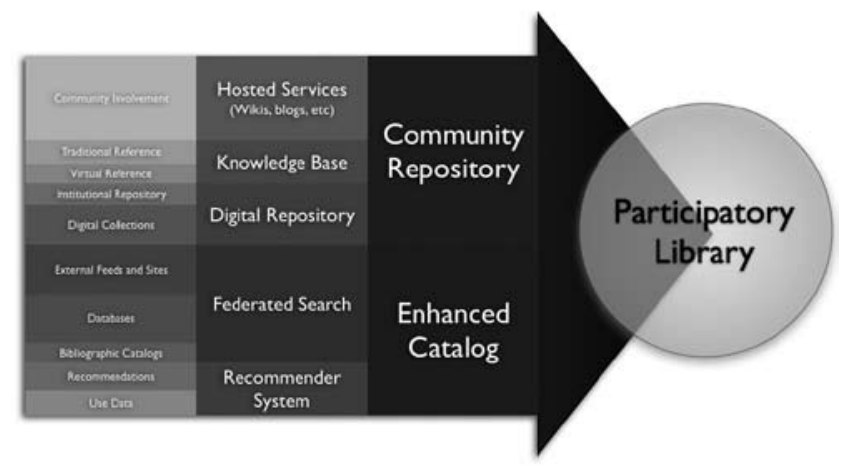

Figure 6: Road map of how the library might make the transition from current systems to a truly participatory system. forums, wikis, and blogs for these community groups to use. If there are standards for these discussion areas, then groups from different communities also could easily participate in shared boards; this makes sense for groups such as Weight Watchers or Alcoholics Anonymous that have local branches and national involvement. In an academic setting, these groups can be student, faculty, or staff organizations or courses.

In addition to reference and hosted community conversations, the library has been actively creating digital collections of materials (either through digitization, leasing service from content providers, or capturing the library's born digital items). Parallel to the digital collection building of library materials is an active attempt to create institutional repositories of faculty papers, teacher lesson plans, organizational documentation, and the like. These services are participatory systems in which collections come from users' contributions, and they may evolve into digital repositories that include both userand librarian-created artifacts.

These different conversations can be archived into a single repository, and, if properly planned, the reference conversations can live alongside, and eventually be intermingled with, the community conversations, and the digital repository (which, after all, though formal, is a community conversation) into a community repository. Community repositories allow librarians to be more easily involved in the conversations of the community and capture important artifacts of these conversations for later use.

\section{Merging library metadata into an enhanced catalog}

Participatory librarianship can be supported by another functional area of the library: collections. Traditionally, the collection comprises books, magazines, and other information resources paid for by the library. Electronic resources, such as databases that are leased instead of purchased, make up a large portion of library expenditures. More recently, Web-based resources (external feeds and sites) have been selected and added to the virtual collection.

Several kinds of finding aids are used to locate these information resources. The catalog and databases both contain descriptions of resources and searching interfaces. In order to improve access, libraries include records for databases within the catalog. Conversely, federated searching tools combine the records from different databases and could allow the retrieval of both books and articles by combining records from the traditional catalog and databases into one tool. If community-created resources are part of the catalog, then these resources also would be findable alongside other traditional library resources.

The tools for describing information resources also can be participatory. In traditional librarianship, the librarians provide metadata that patrons then use to make selections. 
By examining this use data, recommender systems can be created to help users locate new materials. In participatory networking, patrons will be encouraged to add comments about items. If standards are used for these comments, then they can be shared among libraries to create larger pools of recommendations. As these comments are analyzed, they can be combined with usage databases to create stronger recommender systems to present patrons with additional choices based upon what is being explored.

The end result is an enhanced catalog that allows users and libraries to find information regardless of which system the information resides in. However, the enhanced catalog is still just that, a catalog. It contains surrogates of digital information and is managed separately from the artifacts themselves. In the case of physical items, this may be all the library systems can manage, but in the case of digital content, there is one more step that needs to be taken. Namely, the artificial barrier between catalog (defined as inventory control system) and content (housed in the community repository) must come down.

\section{Building the participatory library}

At this point in the evolution of distributed systems into a truly integrated library system, the participatory library, we have two large collections: one of resources, and one of information about the resources. The first collection of digital content, the community repository, is built by the library and its users collaboratively. The second collection, the enhanced catalog, includes metadata, both formal and user-created (such as ratings, commentary, use data, and the like). Both the community repository and the enriched catalog are participatory. Yet to realize the dream of a seamless system of functionality (seamless to the user and the library), these two systems must be merged, allowing users to find resources and, much more importantly, conversations. Furthermore, the users must be able to add to metadata (such as tags to catalog records) and content (such as articles, postings to a wiki, or personal images). The result may be conceived of as a single integrated information resource, which, for the purposes of this conversation, is called the participatory library.

Users may access the participatory library directly through the library or as a series of services in Google, Myspace, or their own home pages. The point is that the access to the library takes place at the point of conversation, not at the point the user realizes he or she needs information from the library.

\section{Conversations and preservation}

The conversation model highlights the need for preservation. Aside from simply providing systems that facilitate conversation, libraries serve as the vital community memory. Conversations construct knowledge, but someone must remember what has already been said and know how to access that dialog. Scientific conversations, for example, are built on previous conversations (theories, studies, methods, results, and hypotheses). Capturing conversations and playing them back at the right time is essential. This might mean the preservation of artifacts (maps, transcripts, blueprints, photographs), but also it means the increasingly important tasks of capturing the digital dialogs. This highlights the need for institutional repositories (that will later be integrated seamlessly with other library systems, as previously discussed). Specifically, Web sites, lectures, courseware, and articles must be kept. Further, they must be kept in true conversational repositories that capture the artifacts (the papers), the methods (data, instruments, policy documents), and the process (meeting notes, conversations, presentations, Web sites, electronic discussions). They must be kept in information structures that make them readily available as conversations; in other words, users must be able to search for materials and reconstruct a conversation in its entirety from one fragment.

\section{Being where the conversation is}

Imagine the conversations that are going on in your local library as you read this. Imagine the physicist chatting with the gardener, and the trustee talking with the volunteer who is reading the latest best-seller. What knowledge can be gleaned from these novel interactions? Can you measure it? Can you enhance it? Can you capture it? Can you recall it when it would be precisely what a user needs?

Note also that these conversations do not belong solely to the library. The library is only part of the conversation. Faced with the daunting variety of resources available on the Web, many organizations try to become the single point of entry into it. Remember that conversations are varied in their mode, places, and players, and, more importantly, that they are intensely personal. This means that participants need to have ownership in them, and often in their locations as well. This also means that the library, as facilitator, needs to be varied in its modes and access points. In many cases, it is better to either create a personal space in which users may converse, or, increasingly, to be part of someone else's space.

What we can learn from Web 2.0's mashups is that smaller sets of limited (but easy to access) functionalities lead to greater incorporation of tools into people's lives. In the ChicagoCrime-Google Maps mashup, combining maps from Google and Chicago crime statistics, it was important for the host of the site to brand the space and shape the interface for his conversation on crime. Can your library functions be as easily incorporated into these types of conversations? Can a user search your catalog and present the results on his or her Web site? The point is that libraries need to be proactive in a new way. Instead of 
the mantra, "Be where the user is," we need to, "Be where the conversation is." It is not enough to be at the users' desktops; you need to be in their e-mail program, in their MySpace pages, in their instant messaging lists, and in their RSS feed readers.

All of these examples point to a significant mental shift that librarians will need to make in moving from delivering information from a centralized location to delivering information in a decentralized manner where the conversations of users are taking place. The catalog example presented earlier is an example of a centralized place for conversations. What if, instead of only being in a catalog, the same data were split into smaller components and embedded in the user's browser and e-mail programs? Just as Google's mail system embeds advertising based upon the content of a message, the Library could provide links to its resources based upon what a user is working on. By disaggregating the information within its system, the Library can deliver just what is needed to a user, provide connections into mashups, and live in the space of the user instead of forcing the user to come to the space of the library.

\section{Challenges and opportunities}

There is clearly a host of challenges in incorporating participatory networks and a participatory model into the library. This is to be expected when we are dealing with something as fundamental as knowledge and as personal as conversations. We consider four major challenges that must be met by libraries before they can truly get into the business of participatory librarianship.

\section{Technical}

There is a rich suite of participatory networking software that libraries can incorporate into their daily operations. Implementing a blog, a wiki, or RSS feeds these days is not a hard task, and they can easily be used to deliver information about library services and conversations to the user's space. Furthermore, these systems are often tested in very large-scale environments and are, in some cases, the same tools used in large participatory networking sites such as Wikipedia and Blogger. Some of these packages are commercial, but others are open source software. Open source software is cheaper, easier to adapt, and, in some cases, more advanced. The downside to open source is that it requires a considerable amount of technical knowledge by the library (but not as much as one might think) and does not come with a technical support hotline.

The largest technological impediment, however, may be the currently installed base of software within libraries. Integrated library systems have a long history and include a broad range of library functions. Legacy code and near monolithic systems have restricted the easy exchange of a diverse set of information. Were these systems written today, they would use modular code and loosely coupled APIs and allow customers much more interface customizability. These changes may come to integrated library systems (as customers are demanding it), but it may take years.

Several libraries are currently attempting to pick apart these integrated systems themselves. Often, libraries go to the underlying databases that hold the library metadata or create their own data structures, such as the University of Pennsylvania Data Farm project. ${ }^{22}$ Once components of this system are exposed, the catalog simply becomes another database that can be federated into new and unified interfaces. However, such integration requires a great deal of technological expertise. There is an opportunity for integrated library system vendors or large consortial groups such as OCLC to move quickly into this space.

In the meantime, there is an opportunity for the larger library community. This technology brief was created in response to a perceived need. Whether evidenced in the Library 2.0 community or in conversations at LITA, libraries are now interested in incorporating new Web technologies into their offerings and operations. The technologies under consideration here present platforms for experimentation. Rather than setting up thousands of separated experiments, however, the library community should create a participatory network of its own. The technology certainly exists to create a test bed for libraries to set up various combinations of communication technologies (blogs, tagging, wikis), to test new Web services against pooled data (catalog data, metadata repositories, and large scale data sets), and even to incorporate new services into the current library offerings (RSS feeds, for example). By combining resources (money, time, expertise) in a single, large-scale test bed, libraries not only can get greater impact for the their investments, but can directly experience life as a connected conversation. These connections, if built at the ground level, will then make it easier for the Library to come into existence. Terminology can be clarified, claims tested, and best practices collaboratively developed, greatly accelerating innovation and dissemination.

\section{Operational}

In addition to being in the conversation business, libraries are in the infrastructure business. One of the most powerful aspects of a library is its ability not only to develop a collection of some type of information, but to maintain it over time. Sometimes infrastructure can be problematic (as in the case of legacy systems), but more often than not it provides a stable foundation from which to operate.

There are many conversations going on that need infrastructure but have none (or little). Think of the opportunities in your community for using the Web to 
facilitate a conversation. It might be a researcher wanting to disseminate the results of his or her latest study. It might be a community organization seeking funding. It might be a business trying to manage its basic operational knowledge. The point is that such individuals and community organizations are not in the infrastructure business and could use a partner who is. Imagine a local organization coming to the library and, within a few minutes, setting up a Web site with an RSS feed, a blog, and bulletin boards. The library facilitates, but does not own, that individual's or organization's conversation. It does form a strong partnership, however, that can be leveraged into resources and support. The true power of participatory networking in libraries is not to give every librarian a blog; it is in giving every community member a blog (and making the librarian a part of the community). In addition, the library can play the role of connecting these conversations to other users when appropriate.

Participatory libraries allow the concept of community center (intellectual center, service center, media center, information center, meeting center) to be extended to the Web. Many public libraries have no problem providing meeting space to local non-profits. Why not provide Web meeting space in the form of a Web site or Web conferencing? Many academic libraries attempt to capture the scholarly output of their faculties, why not help generate the output with research data stores? The answers to these questions inevitably come back to time and money. However, there is nothing in this brief that says such services have to be free. In fact, the best partnerships are formed when all partners are invested in the process. The true problem is that libraries have no idea of how to charge for such services. Faculty would be glad to write library support into grants (in the form of Web site creation and hosting), but need a dollar figure to include and how long each task will take. Many libraries aren't used to positioning their services on a per item basis, and this makes it difficult to build partnerships. Sometimes it is not a lack of money, but a lack of structure to take in money that is the problem.

\section{Policy}

As always, it is policy that presents the greatest challenges. The idea of opening the library functions to a greater set of inputs is rife with potential pitfalls. How can libraries use the technologies and concepts of Facebook and MySpace without being plagued by their problems? How can users truly be made part of the collection without the library being liable for all of their actions? The answers may lie in a seemingly obscure concept: identity management.

Conversations can range in their mode, topic, and duration. They also can vary in the conversants. The library needs to know a conversant's status to determine policy (for example, we can only disclose this information to this person), and requires a unique identifier, such as a library card, to uphold it. In traditional libraries, that is the extent of identity management.

In a participatory model, distinctions among identities become complex and graduated, and require us to consider a new approach. This new model, of patrons adding information directly to library systems, is not as radical as it may first appear. We have become very used to the idea of roles and tiered levels of authority in many other settings. Most modern computer systems allow for some gradation in user abilities (and responsibilities). Online communities have even introduced merit systems, by which continual high-quality contributions to a site equals greater power in the site. Think about Amazon, Wikipedia, even eBay; as users contribute more to the community, they gain status and recognition. From participants to editors, from readers to writers, these organizations have seen membership as a sliding scale of trust, and libraries need to adopt this approach in all of their basic systems. We currently do, to a degree, in the form of librarians, paraprofessionals, and other staff. Yet even these distinctions tend to be rigid and often class-based, with high walls (such as a master's degree) between the strata. Some of this is imposed by outside organizations (civil service requirements, tenure track, and so on), but a great deal is there by inertia of the field.

Skillful use of identity management will help libraries avoid the baggage of MySpace and Facebook. As users grain greater access, greater responsibility, and greater autonomy, libraries need to be more certain of their identities. That is, for a user to do more requires the library to know more. Knowing about a user may involve traditional identity verification or tracking an activity trail, whereby intentions can be judged in relation to actions. These concepts may be expressed as, "The more we know you, the more control you can have in valuable services such as blogging, or the catalog." The concepts are illustrated in Blogger and LiveJournal, both of which require some level of identity information. In another example, to join LiveJournal you must be invited, thus the community confers identity. The common theme is that verifying (and building) identity is communitybased. The difference between the library and MySpace is that the library works in an established community with traditional norms of identity, whereas MySpace is seeking to create a community (where identity is more defined by social connections than actions). Both the library and the services mentioned above, however, base their functions and services on identity.

\section{Ethical}

As knowledge is developed through conversation, and libraries facilitate this process, libraries have a powerful impact on the knowledge generated. Can librarians interfere with and shape conversations? Absolutely. Should we? We can't help it. Our collections, our reference work, 
our mere presence will influence conversations. The question is, in what ways? By dedicating a library mission to directly align with the needs of a finite community, we are accepting the biases, norms, and priorities of the community. While a library may seek to expand or change the community, it does so from within.

When Internet filtering became a requirement for federal Internet funding, public and school libraries could not simply quit, or ignore the fact, because they are agents of their communities. School libraries had to accept filtering with federal funding because their parent organizations, the schools, accepted filtering. ${ }^{23}$ We see, from this example, that libraries may shift from facilitating conversations to becoming active conversants, but they are always doing both. Thus, the question is not whether the library shapes conversations, but which ones, and how actively?

These questions are hardly new to the underlying principles of librarianship. And nothing in the participatory model seeks to change those underlying principles. The participatory model does, however, highlight the fact that those principles shape conversations and have an impact on the community.

\section{Recommendations}

The overall recommendation of this article is that libraries must be active participants in the ongoing conversations about participatory networking. They must do so through action, by modeling appropriate and innovative use of technologies. This must be done at the core of the library, not on the periphery. Rather than just adding blogs and photosharing, libraries should adopt the principles of participation in existing core library technologies, such as the catalog. Anything less simply adds stress and stretches scarce resources even further.

To complement this broad recommendation, the authors make two specific proposals: expand and deepen the discussion and understanding of participatory networks and participatory librarianship, and create a participatory library test bed to give librarians needed participatory skills and sustain a standing research agenda in participatory librarianship.

As stated in the outset of this document, what you are reading is limited. While it certainly contains the kernel and essence of participatory networks (systems to allow users to be truly part of services) and participatory librarianship (the role of librarianship as facilitators and actors in conversations in general), the focus was on technology and technology changes. Already, the ideas contained in this document have been part of an active conversation. The first draft of this document was made available for public comment via a wiki, e-mail, and bulletin boards, and concepts herein presented at conferences and lec- tures. However, there is now a need to broaden the scope and scale of the conversation. The theoretical foundations of participatory librarianship need to be rigorously presented. The nontechnical components of the ideas (and the marriage of nontechnical to technical) need to be explored. There are curricular implications: How do we prepare participatory librarians? The nature and form of the Library and participatory systems need to be discussed and examined in theoretical, experimental, and operational contexts.

In order to do this, the authors propose a series of conversations to engage the ideas. These conversations, both in person and virtual, need to be within the profession and across disciplines and industries. The deeper conversations need to be documented in a series of publications that expand this document for academics and practitioners.

The authors feel, however, that the first proposal must be grounded in action. To complement the more abstract exploration of participatory networks and participatory librarianship, there must be an active playground where conversants can experience firsthand the technologies discussed, and then actively shape the tools of participation. This is the test bed. This test bed would implement a participatory network of libraries, and provide a common technology platform to host blogs, wikis, discussion boards, RSS aggregators, and the like. These shared technologies would be used to experiment with new technologies and to provide real services to libraries. Thus, libraries could not only read about blogging applications, they could try them and even roll them out to their community members. As libraries start new community initiatives, they could rapidly add wikis and RSS feeds hosted at the shared test bed. The test bed would also make all software available to the libraries so they could locally implement technologies that have proven themselves. The test bed would provide the open source software and consulting support to implement features locally. The test bed also would develop new metrics and means of evaluating participatory library services for the use of planners and policy makers.

A major deliverable of the test bed, however, would be to model innovations in integrated library systems (ILS). The test bed would work with libraries and ILS vendors to pilot new technologies and specify new standards to accelerate ILS modernization. The point of the test bed is not to create new ILSs, but to make it easy to incorporate innovative technologies into vendor and open source ILSs.

The location and support model of the test bed are open for the library community to determine. Certainly, it could be placed in existing library associations or organizations. However, it would require the host to be seen as neutral in ILS issues, and to be capable of supporting a diverse infrastructure over time. The host organization also would need to be a nimble organization, able 
to identify new technical opportunities and implement them quickly.

One model that might work is establishing a pooled fund from interested libraries. This pooled fund would support an open source technology infrastructure and a small team of researchers and developers. The team's activities would be overseen by an advisory panel drawn from contributing members. Such a model spreads this investment out into experimentation across a broad collaboration and should, ultimately, save libraries time and money. As a result, the time and money that individual libraries might spend on isolated or disconnected experiments can be invested in a common effort with greater return.

Libraries have a chance not only to improve service to their local communities, but to advance the field of participatory networks. With their principles, dedication to service, and unique knowledge of infrastructure, libraries are poised not simply to respond to new technologies, but to drive them. By tying technological implementation, development, and improvement to the mission of facilitating conversations across fields, libraries can gain invaluable visibility and resources.

Impact and leadership, however, come from a firm and conceptual understanding of libraries' roles in their communities. The assertion that libraries are an indispensable part of knowledge generation in all sectors provides a powerful argument to an expanded function of libraries. Eventually, blogs, wikis, RSS, and AJAX all will fade in the continuously dynamic Internet environment. However, the concept of participatory networks and conversations is durable.

\section{Acknowledgements}

The authors would like to thank the following people and groups: Ken Lavender, for his editing prowess. The doctoral students of IST 800 for providing input on conversation theory: Johanna Birkland, John D'Ignazio, Keisuke Inoue, Jonathan Jackson, Todd Marshall, Jeffrey Owens, Katie Parker, David Pimentel, Michael Scialdone, Jaime Snyder, Sarah Webb. The students of IST 676 for their tremendous input and for their exploration of the related concept of Massive Scale Librarianship: Marcia Alden, Charles Bush, Janet Chemotti, Janet Feathers, Gabrielle Gosselin, Ana Guimaraes, Colleen Halpin, Katie Hayduke, Agnes Imecs, Jennifer Kilbury, Min-Chun Ku, Todd McCall, Virginia Payne, Joseph Ryan, Jean Van Doren, Susan Yoo. Those who commented on the draft, including Karen Scheider, Walt Crawford and John Buschman, and Kathleen de la Peña McCook. LITA for giving us a forum for feedback. Carrie Lowe, Rick Weingarten, and Mark Bard of ALA's OITP for their feedback and support. The Institute staff, including Lisa Pawlewicz, Joan Laskowski, and Christian O’Brien, for logistical support.

\section{References and Notes}

1. Cited in P. Hardiker and M. Baker, "Towards Social Theory for Social Work," Handbook of Theory for Practice Teachers in Social Work, J. Lishman, ed. (London: Jessica Kingsley, 1991).

2. G. Pask, Conversation Theory: Applications in Education and Epistemology (New York: Elsevier, 1976).

3. Linda H. Bertland, "An Overview of Research in Metacognition: Implications for Information Skills Instruction," School Library Media Quarterly 15 (Winter 1986): 96-99.

4. Pask, Conversation Theory, 92.

5. Tim O'Reilly, "What Is Web 2.0: Design Patterns and Business Models for the Next Generation of Software," O'Reilly, www.oreillynet.com/pub/a/oreilly/tim/news/2005/09/30/ what-is-web-20.html (accessed Feb. 1, 2007).

6. J. Suroweicki, The Wisdom of Crowds (New York: Doubleday, 2004)

7. “Wiki's Wild World: Researchers Should Read Wikipedia Cautiously and Amend It Enthusiastically," Nature 438, no. 890 (Dec. 2005): 890; www.nature.com/nature/journal/v438/ n7070/full/438890a.html (accessed Feb 1, 2007).

8. Google, "Google Maps API," www.google.com/apis/ maps (accessed Feb. 1, 2007).

9. "Java Script Tutorial," W3 Schools, www.w3schools.com/ js/default.asp (accessed Feb. 1, 2007).

10. While the terms in Web 2.0 are a bit ambiguous, many people confuse the term "mashup" with "remixes." Mashups are combining data and functions (such as mapping), whereas remixes are reusing and combining content only. So combining a song with a piece of video to create a "new" music video would be a remix. Mapping all of your videos on a map using YouTube to store the videos and Google Maps to plot them geographically would be a mashup.

11. For example Gmail, a very widely used, Web-based email service, but is still considered "beta" by Google.

12. Malcolm Gladwell, The Tipping Point: How Little Things Can Make a Big Difference (Boston: Back Bay Books, 2000), 272.

13. OCLC, "Introduction to Dewey Decimal Classification," www.oclc.org/dewey/versions/ddc22print/intro.pdf (accessed Feb. 1, 2007).

14. “Ajax (programming)," Wikipedia, http://en.wikipedia .org/wiki/Ajax_(programming) (accessed Feb. 1, 2007).

15. "Web Services Activity," W3C, www.w3.org/2002/ws (accessed Feb. 1, 2007).

16. Walt Crawford, "Library 2.0 and 'Library 2.0.'" Cites $\mathcal{E}$ Insights 6, no. 2 (2006), http:// citesandinsights.info/civ6i2.pdf (accessed Dec. 13, 2007).

17. Eric Ormsby, "The Battle of the Book: The Research Library Today," The New Criterion (Oct. 2001): 8.

18. Ken Chad and Paul Miller, "Do Libraries Matter? The Rise of Library 2.0: A White Paper," version 1.0, 2005, www.talis .com/downloads / white_papers / DoLibrariesMatter.pdf (accessed Feb. 1, 2007).

19. Slashdot, "MySpace \#1 US Destination Last Week," http: / / slashdot.org/articles / 06/07/12/0016211.shtml 
(accessed Feb. 1, 2007); Pete Williams, "MySpace, Facebook Attract Online Predators," MSNBC, www.msnbc.msn.com/ id/11165576 (accessed Feb. 1, 2007); "The MySpace Generation," BusinessWeek, Dec. 12, 2005, www.businessweek .com/magazine/content/05_50/b3963001.htm (accessed Feb. 1, 2007).

20. Saturday Night Live, "Sketch: MySpace Seminar," NBC, www.nbc.com/Saturday_Night_Live/segments/9166.shtml (accessed Feb. 1, 2007).
21. C. Stohl and G. Cheney, "Participatory Processes/Paradoxical Practices," Management Communication Quarterly 14, no. 3 (2001): 349-407.

22. J. Zucca, "Traces in the Clickstream: Early Work on a Management Information Repository at the University of Pennsylvania," Information Technology and Libraries 22, no. 4 (2003): $175-78$.

23. To be more precise, public and school libraries that accept e-Rate funding. 